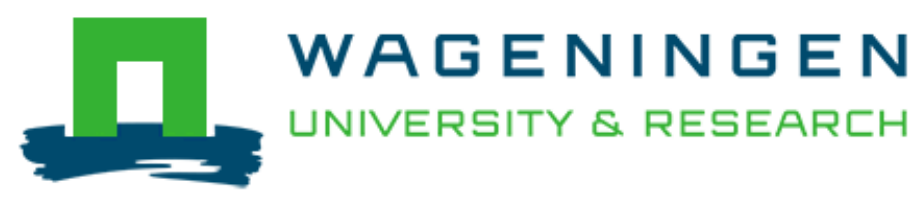

\title{
Review of analytical approaches for the identification of non-intentionally added substances in paper and board food contact materials
}

Peters, R. J. B., Groeneveld, I., Sanchez, P. L., Gebbink, W., Gersen, A., de Nijs, M., \& van Leeuwen, S. P. J.

This is a "Post-Print" accepted manuscript, which has been published in "Trends in Food Science and Technology"

This version is distributed under a non-commercial no derivatives Creative Commons (c) (1) $(9)$ reproduction in any medium, provided the original work is properly cited and not used for commercial purposes. Further, the restriction applies that if you remix, transform, or build upon the material, you may not distribute the modified material.

Please cite this publication as follows:

Peters, R. J. B., Groeneveld, I., Sanchez, P. L., Gebbink, W., Gersen, A., de Nijs, M., \& van Leeuwen, S. P. J. (2019). Review of analytical approaches for the identification of non-intentionally added substances in paper and board food contact materials. Trends in Food Science and Technology, 85, 44-54. DOI: 10.1016/j.tifs.2018.12.010 You can download the published version at:

https://doi.org/10.1016/j.tifs.2018.12.010 


\section{Accepted Manuscript}

Review of analytical approaches for the identification of non-intentionally added substances in paper and board food contact materials

Ruud J.B. Peters, Iris Groeneveld, Patricia Lopez Sanchez, Wouter Gebbink, Arjen Gersen, Monique de Nijs, Stefan P.J. van Leeuwen

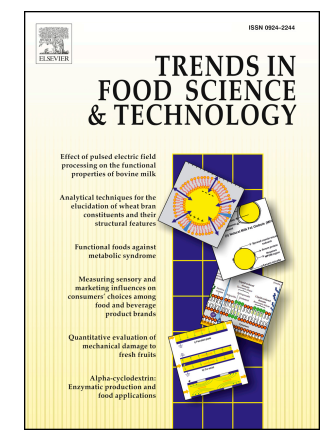

PII:

S0924-2244(18)30445-X

DOI: https://doi.org/10.1016/j.tifs.2018.12.010

Reference: TIFS 2385

To appear in: Trends in Food Science \& Technology

Received Date: 28 June 2018

Revised Date: 24 November 2018

Accepted Date: 28 December 2018

Please cite this article as: Peters, R.J.B., Groeneveld, I., Sanchez, P.L., Gebbink, W., Gersen, A., de Nijs, M., van Leeuwen, S.P.J., Review of analytical approaches for the identification of non-intentionally added substances in paper and board food contact materials, Trends in Food Science \& Technology, https://doi.org/10.1016/j.tifs.2018.12.010.

This is a PDF file of an unedited manuscript that has been accepted for publication. As a service to our customers we are providing this early version of the manuscript. The manuscript will undergo copyediting, typesetting, and review of the resulting proof before it is published in its final form. Please note that during the production process errors may be discovered which could affect the content, and all legal disclaimers that apply to the journal pertain. 
1 Review of analytical approaches for the

2 identification of non-intentionally added

3 substances in paper and board food contact materials

5

Ruud J.B. Peters ${ }^{1 *}$, Iris Groeneveld ${ }^{1}$, Patricia Lopez Sanchez ${ }^{1,2}$, Wouter Gebbink ${ }^{1}$, Arjen Gersen $^{1}$, Monique de Nijs ${ }^{1}$ and Stefan P. J. van Leeuwen ${ }^{1}$

${ }^{1}$ RIKILT - Wageningen University \& Research, 6700 AE Wageningen, The Netherlands

${ }^{2}$ King Abdullah University of Science and Technology (KAUST), Core Labs, Thuwal, 23955-6900, Saudi Arabia

* Corresponding author (e-mail: ruudj.peters@wur.nl)

\section{Abstract}

Background

Food contact materials (FCM) may contain non-intentionally added substances (NIAS) as a result of reaction by-products, oligomers, degradation processes, chemical reactions between packaging materials and foodstuff, or as impurities from the raw materials used for their production.

\section{Scope and Approach}

In this review, current approaches for the detection and identification of NIAS from paper and board FCM are presented. Reviewed are the definition of NIAS, approaches for NIAS identification and quantification, the comprehensive analysis of NIAS and the role of in silico tools and bioassays.

Key Findings and Conclusions

NIAS in paper and board are mostly components from printing inks, adhesives, sizing agents and surface coatings. Recycled paper contains overall more NIAS than fresh paper. Targeted analysis is generally performed for predicted NIAS, whereas a untargeted, or full-scan screening method is applied to detect and identify unpredicted NIAS. Sample preparation and contact conditions fall in two categories; migration and extraction. Migration studies are performed with food simulants while extraction studies are Soxhlet or ultrasound assisted solvent extraction. In untargeted analysis in silico tools are gaining importance in the identification of NIAS. Bioassays are used to determine the bioactivity of extracts or fractions in order to assess the potential toxicity of NIAS present in the mixture. A combination of bioassays and chemical analysis is used to direct the identification of unknown bioactive NIAS in complex mixtures like those from paper and board FCM. However, future research is required into the selection of bioassays since these should not only be sensitive enough for detecting all compounds of concern but should also have a relevance with human health.

Key words: food contact materials, non-intentionally added substances, chemical analysis, bioassay, effect directed analysis, in silico tools 


\section{Introduction}

The purpose of food contact materials (FCM) is to package and protect food during transport and storage, to increase shelf life or for marketing purposes. It includes all materials and articles intended to come into contact with food. The FCM are produced from raw materials and so called intentionally added substances (IAS) which increase shelf-life but also enhance the manufacturing, the stability, and mechanical properties of the FCM itself. Examples of IAS include monomers, prepolymers, antioxidants, lubricants, surfactants and UV stabilisers. In addition to IAS, FCMs may also contain non-intentionally added substances (NIAS) which originate from reaction by-products, oligomers, degradation processes, chemical reactions between the packaging materials and the foodstuff, or as impurities from the raw materials used for their production. Among all food packaging materials, paper and board are most commonly used after plastics. Approximately $37 \%$ of all food packaging materials is made from paper and board of which circa $20 \%$ accounts for FCMs (Muncke, 2012; Trier et al., 2011a). Consumers are therefore very likely to eat food that is packed in paper or board. It comes without saying that food packaging should be safe at all times, however, porous materials like paper and board offer not much resistance towards the migration of chemical compounds. Direct contact with the foodstuff is not a requirement for migration to occur: compounds can migrate through the paper or board into the foodstuffs (Bengtström et al., 2014; Eicher et al., 2015). The presence of, possibly toxic, NIAS is often not known by the manufacturer itself (Geueke, 2013).

The phenomenon of NIAS is not new, but has raised awareness since they were specifically mentioned in Article 19 of Regulation EU 10/2011 (European Commission, 2011). This Regulation states that: "NIAS are permitted in final plastic articles, but should be assessed by the manufacturer in accordance with international recognised scientific principles on risk assessment". On January 28, 2016, the European Food Safety Authority (EFSA) Panel on Food Contact Materials, Enzymes, Flavourings and Processing Aids concluded that the required toxicity data for substances in FCM's (IAS and NIAS) should be related to the expected human exposure and proposed three threshold levels of human exposure as triggers for requiring additional toxicity data: 1.5, 30 and 80 $\mu \mathrm{g} / \mathrm{kg}$ body weight/day (EFSA, 2016). However, often a quantitative analysis of NIAS is not possible since reference standards are not available. In terms of risk assessment only NIAS up to a molecular weight of 1,000 Daltons ( $\mathrm{Da}$ ) have to be considered with the exception of fluorocarbons for which this threshold is $1500 \mathrm{Da}$ since at the same molecular weight, fluorocarbons tend to have a smaller molecular volume. These thresholds are important as EFSA has conventionally assumed in its assessments of plastic starting materials that above these molecular weights, substances are not absorbed by the body and therefore may be excluded from any calculations of migration and exposure. However, it's not unthinkable when dealing with polymers, that compounds with a higher molecular weight may be subjected to an in vivo hydrolysis, thus generating smaller oligomers that can be absorbed. In a recent paper Groh et al. (2017) point to the existence of large population subgroups with an increased intestinal permeability which may lead to a higher of compounds of high molecular weight. They recommend reconsidering the use of the 1000 Da molecular weightbased cut-off in toxicity and risk assessment of FCM migrates

Currently, there is special attention for recycled paper and board FCMs due to the varying and often unknown origins of the raw materials. Some materials contain significant amounts of substances with detrimental health effects and are not supposed to come into contact with food (Biedermann \& Grob, 2010; Biedermann \& Grob, 2013a). An example are mineral oils and aromatic hydrocarbons resulting from printing inks. Furthermore, the solvents and procedures used for the paper recycling process can contribute to the formation of new molecules as well, which are then also classified as NIAS (Chalbot et al., 2006). The incorrect recycling of food packaging materials that consist of multiple layers, like beverage carton (also called 'liquid paperboard') for the 
packaging of drinks, could contribute to a significant increase of NIAS. While an official guidance of how NIAS should be assessed and reported is currently not available, an initial guidance on risk assessment of NIAS is provided by ILSI (Koster et al. 2015). In this review an overview is presented of the various strategies that are currently applied to detect and identify NIAS in paper and board FCM.

\section{NIAS Classification}

The sources from which NIAS emerge vary, and can be divided into reaction by-products, oligomers, break-down or degradation products, impurities from raw materials, side products or neo-formed compounds, and contaminants picked up during the production or recycling process. Degradation products can be further divided into degradation of polymers, and degradation of additives (Figure 1).

Figure 1. Classification of NIAS (Geueke, 2013; Koster et al., 2015).

One of the most frequent pathways to NIAS formation are degradation processes. Degradation can occur to the base material itself, but also to the additives added to improve the physicochemical properties of the final FCM. As a result of, for example, exposure to microwaves and other heating processes, irradiation for sterilization purposes, misuse of the packaging by the consumer, or just by natural ageing, molecules with a lower molecular weight can be formed (Bignardi et al., 2017). These have higher diffusion coefficients compared to higher molecular weight chemicals, thus possess a higher risk to migration into food than the original molecules (Nerin et al., 2013).

There are also additives which are added to the FCM to enhance their properties. Examples of these are antioxidants or light stabilizers. Degradation of the antioxidants Irganox 1010 and Irgafos 168 to hydrolysed and oxidized forms has been studied (Burman et al., 2005; Alin \& Hakkarainen, 2011; Yang et al., 2016). Another example are the alkylphenols, octyl- and nonylphenol, which can be generated by the oxidation of tris(nonylphenol)phosphite (TNPP). TNPP is used for performance enhancement of certain polymer resins, such as polyvinyl chloride (PVC), acrylics and polyolefins, especially PE (Mottier et al., 2014). Alkylphenols can also arise from the degradation of polyethoxylated nonylphenols, which are surfactants in cleaning agents commonly used in PET bottle manufacturing and in other materials such as adhesives or polymeric dispersions (Nerin et al., 2013).

Equally important NIAS are the impurities in the raw materials and additives used to produce food packaging materials or articles. As far as they are relevant for the risk assessment, the main impurities of a substance should be considered, and if necessary be included in the specifications document by the manufacturer. However, it is not always possible to list and consider all impurities during the authorization. An example of such a situation is the presence of primary aromatic amines (PAAs) and $\beta$-naphthol in azo-pigments made for printing inks. Both substances can be present as impurities in the pigment and in the final ink formulation. The azo-pigment itself is an IAS used to formulate the ink, but PAAs and $\beta$-naphthol or $\beta$-naphthol-derivates are NIAS (Koster et al., 2015). Another case is the presence of impurities from acrylic adhesive additives in migration tests of multilayer materials (Canellas et al., 2010a).

Side products or neo-formed NIAS may be generated during the manufacturing process or as a result of the use of the food packaging by the consumer. These type of compounds can also be a 
product from interactions between compounds in the FCM and the foodstuff. An example of neoformed NIAS are PAAs in polyurethane (PU) adhesives. PU adhesives are formed by the polymerization of polyols and diisocyanate monomers. If the adhesive has not been properly cured or if the ingredients have not been properly mixed, the polymerization reaction is not efficient enough and the remaining non-polymerized aromatic isocyanates can produce PAAs in contact with water (Pezo et al., 2012). In addition to PAAs, other NIAS may be formed from adhesives (Félix et al., 2012). Epoxy-based lacquers may contain bisphenol A (BPA) and bisphenol A diglycidyl ether (BADGE). Reaction products of BADGE with food proteins have also been reported (Coulier et al., 2010).

Finally, contaminants from the recycling process are also considered as NIAS and need to be included in the risk assessment if they have the potential to migrate into the foodstuff (Pivnenko et al., 2015). Contaminants are different from impurities, in the sense that contaminants are included during the production or during the lifetime of the FCM. Contaminants present in recycled paper and board FCMs may originate back to the previous function of the paper material, but can also result from the misuse of the packaging by the consumer before discarding it. An example is the presence of BADGE in uncoated recycled paper or board fibres, when this compound has been used in epoxy-based coatings for the previous state of the paper or board (Suciu et al., 2013). Mineral oil saturated hydrocarbons (MOSH) and mineral oil aromatic hydrocarbons (MOAH) mainly from printing inks (e.g. of recycled newspaper), perfluorinated compounds, such as perfluorinated acids (PFCA) and sulfonates (PFAS), are other examples of these type of NIAS. It should be noted that these kinds of contamination often regards reusable items that are subjected to ageing and damage but this eventuality is not considered by any Regulation. There is no such thing as an "expiring date" for articles intended for repeated use, both for domestic and industrial use (Geueke et al. 2018). The remainder of this paper will focus on NIAS in paper and board.

\section{Approaches for NIAS identification}

Analysis of NIAS has proven to be very challenging, since their presence or identity is often not known, however, sometimes predictions can be made. Therefore, the first step of the analysis and identification process should involve the collection of information about compounds that may be present in the FCM, NIAS as well as IAS. Van Bossuyt et al. published a list of substances known and used in printed paper and board FCMs (Van Bossuyt et al., 2016). They evaluated 6073 compounds on safety and physicochemical data and compared them to other official lists that are described in their study. From all identified and classified compounds, $42 \%$ was classified as a single substance, $20 \%$ as resulting from polymers, $18 \%$ as mixtures, and $20 \%$ was assigned to other substances including metal complexes and inorganic substances. The major sources of compounds found in paper and board are components from printing inks, adhesives, sizing agents, surface coatings, impurities in the raw materials and from the manufacturing process (Nerin et al., 2013; Muncke, 2011). Compounds that are regularly used or detected in paper and board are primary aromatic amines, BPA, BADGEs and related compounds, perfluorinated compounds, phthalates, printing inks and mineral oils. Table 1 gives an overview of different classes of compounds detected in paper and board. There are many other additives being used for paper and board food packaging to increase shelf-life, e.g. antioxidants, sizing agents, wet strength resins, colorants, and fillers. Antioxidants like Irganox 1010 and Irgafos 168 are added to the packaging material to prevent oxidation processes. The collection of information is then followed by chemical analysis of NIAS with the appropriate sample preparation and analysis techniques.

For the analysis of predicted or unpredicted NIAS, two strategies may be applied: targeted analytical methods for the analysis of predicted NIAS or non-targeted or screening methods to 
analyse substances with a wide range of physical/chemical properties. All analysis strategies should detect and quantify the amount of NIAS present in the FCM. This is possible for predicted and known NIAS, but difficult for unpredicted NIAS since reference standards may not be available. As a practical standard, the migration level of $10 \mu \mathrm{g} / \mathrm{kg}$ food for NIAS is applied, as this is the level from which each migrated substance must be identified. There are quite some techniques and ways to prepare a paper or board sample prior to analysis, mostly depending on the goal of the research. In general, these methods can be divided into the category 'migration studies' and 'extraction methods'. In migration studies the migration of NIAS from the FCM into a simulated food matrix is studied. While this results in more meaningful results the simulated food matrices are not always easy to analyse. In extraction studies the potential release of NIAS by an FCM is studied which often results in an overestimation of the types and quantities of NIAS that are released. An alternative strategy to determine NIAS is reported by Bignardi et al. (2014) who reported experiments of complete dissolution of materials in order to identify NIAS in the item. NIAS from paper and board can also be done by direct analysis of the FCM. Headspace analysis (Nerin et al., 2004) or direct MS techniques such as DART (direct analysis in real time) have been applied (Bentayeb et al., 2012). Analysis of foodstuffs have been performed less when the objective was to know what compounds were part of the packaging material (Bignardi et al., 2018).

\subsection{NIAS extraction}

Food simulants are used for migration studies to literally simulate which compounds can migrate from the FCM into the foodstuff it was supposed to hold. Therefore, it is important to use a proper simulant that represents the same properties as the foodstuff. Food simulants like Tenax, water or organic solvents have been used to simulate migration of NIAS from packaging (Bignardi et al., 2017; Bentayeb et al., 2007; Aznar et al., 2016), adhesive formulas (Félix et al., 2012; Canellas et al., 2012), and paper and board FCMs (Suciu et al., 2013; Bradley et al., 2008; Parigoridi et al., 2014). Commission Regulation (EU) No 10/2011 (Annex III) on plastic materials and articles intended to come into contact with food, contains a list of recommended food simulants to be used for certain food types. Since the concentration of NIAS are often quite low in migration extracts, concentration steps may be applied before analysis of the sample. In the Biosafepaper project (Bradley et al., 2008) a review was done on the use of bioassays for the safety assessment specifically on paper and board FCMs. It was advised to use water as a simulant for wet foods, $95 \%$ ethanol for fatty foods, and Tenax as a simulant for FCMs in contact with dry foods. After sufficient exposure of the FCM to the Tenax powder, the compounds can be extracted from the Tenax by $95 \%$ ethanol. Compatibility of the extraction solvent with the bioassays should be considered, however it is also possible to transfer the FCM extract to another more suitable solvent, as was done by Koster et al. (2014).

Besides migration studies, there are many other extraction methods that can be applied to paper and board FCMs. The extraction of these compounds has often been divided into two parts, one constituting of volatiles, and the other of semi- and non-volatile compounds. Volatile compounds have been extracted from paper and board, as well as from polymer packaging using headspacesolid phase micro extraction (HS-SPME) (Burman et al., 2005; Félix et al., 2012; Sanchis et al., 2017; Kassouf et al., 2013; Canellas et al., 2012), normal headspace extraction (Castle et al., 1997a), and purge-and-trap methods (Bengtström, 2014). Many extractions have also been performed by application of Soxhlet (Bengtström et al., 2014; Chalbot et al., 2006; Bengtström, 2014; Canellas et al., 2012; Bradley \& Coulier, 2007; Weber et al., 2006; Vera et al., 2013) or reflux distillation (Bengtström, 2014; Bengtström et al., 2016; Bhunia et al., 2013; Ozaki et al., 2005; Brenz et al., 2016) to obtain semi- and non-volatile compounds from paper and polymer 
samples. Other extraction and clean-up methods involved ultrasound-assisted solvent extraction (UAE) (Parigoridi et al., 2014), regular solvent extraction (Bradley et al., 2008; Castle et al., 1997), solid phase extraction (SPE) (Pezo et al., 2012), liquid-liquid extraction (LLE) (Ozaki et al., 2005), focused ultrasonic solid-liquid extraction (FUSLE) (Pérez-Palacios et al., 2012), and Quechers (Sanchis et al., 2017). The choice of extraction method must match the type of analysis technique and some examples of the different approaches to NIAS detection and identification will be discussed.

\subsection{Targeted analysis}

After the compounds have been extracted and are dissolved in the right solvent, NIAS known or predicted to be present can be analysed using targeted analytical methods. The choice of the analytical method and detector should be based on the class of compound that has to be analysed, although, in most cases mass spectrometry (MS) is used. Volatile compounds have generally been analysed by methods based on gas chromatography coupled to MS (GC-MS) (Biedermann \& Grob, 2010; Chalbot et al., 2006; Bradley et al., 2013; Parigoridi et al., 2014; Fierens et al., 2012) and semi- and non-volatile compounds by GC- and liquid chromatography mass spectrometry (LC-MS) based methods (Trier et al., 2011a; Pezo et al., 2012).

Fierens et al. (2012) studied the presence of phthalate compounds in 400 food products and packages sold on the Belgian market. Four different extraction methods were set up, based on the sample being either high-fat foods, low-fat foodstuffs, aqueous-based beverages, or packaging material, and analysis was performed by means of GC-MS with electron ionization (EI). Parigoridi et al. analysed 3 types of recycled cardboards on the presence of 5 organic pollutants by means of GC-EI-MS, and applied UAE with dichloromethane as an extraction method, but also performed a migration experiment with Tenax (Parigoridi et al., 2014). Rubio et al. (2012) have analysed triazines in the presence of NIAS by means of GC-EI-MS in full scan mode, equipped with a programmed temperature vaporizer inlet (PTV). They studied the possibility of using PTV, together with chemometrics, as a tool to spot the presence, and to identify unknown compounds that coeluted with the triazines. This was achieved without the need for calibration or the use of reference samples. Felix et al. (2012) used SPME-GC-MS with KOVATS indeces and the databases ChemSpider and SciFinder to identify the potential migrants from PU adhesives. The presence of two NIAS (1,6-dioxacyclododecane-7,12-dione and 1,4,7-trioxacyclotridecane-8,13-dione) was confirmed in the extracts from migration tests.

Bradley et al. (2013) analysed ink compounds in 350 different foodstuffs packaged in printed paper or board. In total, the presence and concentration of 20 specific UV-cured printing ink compounds in solvent extracts of all foods was determined by GC-MS. Sample preparation included the onpack instructions for heating, to simulate a real-life situation before both the foodstuff and the packaging were separately stored in the freezer. The printing ink compounds were extracted from the foodstuffs by solvent extraction with acetonitrile and dichloromethane, followed by a sample clean-up and a concentration step before they were analysed with GC-MS analysis. For confirmation of the identity of the analyte, the relative retention time and the ion ratios were calculated. For each analyte that was confirmed to be present in the foodstuff, a complementary analysis was performed on the packaging to demonstrate that the source of the compounds was due to migration from the printed paper or board. Nine out of the 20 compounds were confirmed to be present in the foods as well as in the packaging itself, which indicates that these compounds migrated from the packaging. Nguyen et al. (2017) studied the indirect migration of compounds from printing ink from paper and board to food. This study proposes the mechanisms of migration when food is separated from cardboard by a plastic layer. Aliphatic and aromatic mineral oils, 
photo-initiators and plasticisers are used as model compounds to identify critical substances and to estimate the plastic film's thickness to avoid contamination. In much the same way Clemente et al. (2016) discussed the migration of compounds from printing inks in multilayer food packaging materials using GC/MS analysis and pattern recognition with chemometrics. Retail samples were analysed UV-cure ink photo-initiators by Castle et al. (1997b) and Koivikko et al. (2010). Both used LC methods and found these compounds in newly produced cardboard as well as in recycled cardboard.

PAAs and NIAS were analysed in industrial laminates prepared from PU adhesives by Pezo et al. (2012). They reported on a method for the quantification of 18 PAAs by ultra-high performance liquid chromatography coupled to a tandem mass spectrometer (UHPLC-MS/MS), whilst NIAS, impurities and other migrants were identified by UHPLC coupled to quadrupole time of flight mass spectrometry (QTOF). Samples were extracted using SPE based on cation exchange to have optimal retention for the protonated migrants. After elution of the migrants from the SPE cartridge with a $5 \%$ solution of ammonia $\left(\mathrm{NH}_{3}\right)$ in methanol $(\mathrm{w} / \mathrm{v})$ these were separated on a reversed phase C18 column with a mobile phase of methanol and water. The quantification of each PAA by electrospray ionisation (ESI) UHPLC-MS/MS was performed using a chemical standard for each analyte. To identify all other compounds from the migration extract, QTOF was used. The identification of NIAS was performed with its respective mass fragment, combining the software tools MarkerLynx XS $\AA$, ChromaLynx $®$ XS and MassFragment $\AA$ with the chemical databases of PubChem $\AA$, ChemSpider $\AA$ and SciFinder $\AA$ for searching the chemical structures. Next to all PAAs, Pezo et al. achieved to detect and identify a total of 40 NIAS in the 18 samples using this method. Table 1 contains an overview of analytical methods that were used for the targeted analysis of different classes of compounds in paper and board FCMs.

\subsection{Comprehensive analysis for untargeted NIAS}

For the identification of unknown and unpredicted NIAS a comprehensive analysis is used. All analytes must be included, which makes it a challenging task. After screening analysis for NIAS is completed, usually a 'forest of peaks' of unknown compounds will be faced for evaluation, and elaborate compound databases and software tools are needed for the identification (Leeman \& Krul, 2015). It was even stated by Biedermann \& Grob (2013b) that it is not possible to detect and identify all migrants in paper FCM by comprehensive analysis. Biedermann \& Grob determined potentially health-relevant components in recycled paperboard used for packaging dry foods. Compounds were extracted from the paperboard by immersion in a mixture of ethanol/hexane $1: 1$ for 3 days, and the extracts were then concentrated in ethanol and separated into seven fractions by HPLC. Using comprehensive two-dimensional GC (GCXGC) with TOF-MS, they detected over 250 substances that exceeded their detection limit (LOD) of $10 \mu \mathrm{g} / \mathrm{kg}$ in food. From all detected compounds, of the directly analysed extracts, 159 compounds were tentatively identified, whereas 55 in the extracts following silylation. The name of a substance was assigned to a peak when there was convincing agreement with a mass spectrum and the corresponding retention time that were available in the libraries. Above all, it was also considered whether the compound could be present in recycled paperboard. When the mass spectrum of a compound was not present in the libraries, it could not be identified. This research shows the complexity of extracts from recycled paperboard and the demand for large databases and compound libraries to identify the unknown.

Canellas et al. (2015) combined non-targeted analysis by GC-MS with UPLC-QTOF-MS to identify compounds migrating from water-based biodegradable adhesives through multi-layered paper. To identify the composition of the adhesives alone, solutions of these were made in methanol and volatiles were analysed by GC-MS, whilst non-volatiles were analysed by UPLC-QTOF-MS. A migration study was performed by covering cut-outs of the samples with Tenax, storing it for 10 days at $40^{\circ} \mathrm{C}$, after which the samples were extracted with methanol. The National Institute of 
Standards and Technology (NIST) mass spectral search program (v2.0) was used for identification of the GC data. The procedure for the identification of peaks in the GC-MS chromatogram was as follows. First, the chromatograms were subjected to the NIST library, and the assigned compounds were examined for their presence in the adhesives. The peaks that could not be explained as being a regular constituent of the adhesive, were further investigated in the literature. The UHPLC-QTOFMS was equipped with an atmospheric pressure ionization (APCI) source and acquisition was done in both full scan as well as all ion fragmentation mode. Two criteria were used to assign a molecular formula to each accurate mass: (1) the isotopic fit, which is the match of the theoretical isotope pattern with the one in the measured spectrum, and (2) the mass tolerance, which was set at $3 \mathrm{mDa}$ absolute. Once this was done, ChemSpider ${ }^{\circledR}$ and SciFinder $\AA$ were used to identify possible compounds, together with the knowledge of what a general adhesive consists of. Doing this, three non-volatile compounds could be identified, whereas four peaks were left as unidentified. These peaks were later identified by using findings from other studies, and knowledge on what reactions could occur between the regular constituents in the adhesive.

In some cases, NIAS identification is not possible due to the co-elution of compounds. Ion-mobility mass spectrometry (IM-MS) has been recently developed and enables the separation of compounds based on their collision cross section. This novel technique has been recently successfully applied to confirm the migration of colorants (Solvent Red49), plasticisers (dimethyl sebacate, tributyl oacetyl citrate), surfactants (Schercodine $M$, triethyleneglycol caprilate) and an oxidation product of an ink additive (triphenyl phosphine oxide) in multilayers FCM (Aznar et al., 2016). IM-MS can be easily used for paper and board FCM.

An untargeted strategy aiming at identifying NIAS migrating from polyester-polyurethane lacquers from paper and board was developed by Omer et al. (2018). In this innovative approach samples were extracted with acetonitrile and analysed by UHPLC-Q-Orbitrap MS. Data was acquired in the full scan mode and post-acquisition data analysis performed under an open source programming $\mathrm{R}$ environment. Parameters were optimized for noise filtering and deconvolution to resolve co-eluting ions. Software was used to generate elemental formulas for the accurate masses of the identified compounds peaks. A homemade database, populated with predicted polyester oligomer combinations from a relevant selection of diols and di-acids, enabled highlighting the presence of 14 and 17 cyclic predicted polyester oligomers in the samples. Table 2 contains an overview of untargeted analytical techniques used to obtain an overview of all compounds present in paper or board FCMs, adhesives and coatings. Figure 2 presents a decision-tree diagram for the chemical identification of NIAS.

Figure 2. A decision-tree diagram for the chemical identification of NIAS.

\subsection{Combining chemical analysis and bioassays}

The non-targeted chemical analysis of many compounds in paper and board extracts lead to the so called 'forest of peaks' in chromatography, and is very difficult to interpret (Bradley et al., 2008). Rich databases are required which is generally not a problem for GC-MS analyses, but has proven to be more challenging for LC-MS analyses. In terms of safety assessment, information from literature may help, but only when a compound is fully characterised, thus bio-assays will have to be applied at some stage (Severin et al., 2017). An optimum would be achieved when chemical analysis is complemented in a way that in vitro bioassays can predict toxicity of those compounds. By doing so, toxicologically irrelevant compounds can already be excluded from chemical analysis, turning the forest of peaks into just a stand of trees. Severin et al. (2017) recently reviewed all reported in vitro bioassays applied to FCM and concluded that the best way to test finished FCM seems to use screening reporter gene assays. However, the different experimental conditions when performing bioassays (FCM extraction, evaporation/concentration steps, and solubilisation in a 
biocompatible solvent) make comparison between the data very difficult. Groh and Muncke (2017) prepared a similar review and focused 3 main types of toxicity, namely cytotoxicity, genotoxicity, endocrine activity and several whole-organism bioassays. While they conclude that in vitro bioassay-based testing of the toxicity of FCMs is possible they also mention a number of remaining challenges. Areas in need of additional research are the sample preparation of FCMs for bioassay testing, the selection of the appropriate bioassay and the interpretation of the results.

Bioassays and chemical analysis have been combined by different researchers. Rosenmai et al. (2017) reported on an effect-directed strategy that can identify hazards posed by FCMs made from paper and board, including the identification of chemicals responsible for the observed activity. In total 20 FCMs were tested in eight reporter gene assays and as a proof of principle two samples were carried through the complete multi-tiered approach resulting in the identification of specific compounds and their contribution to the observed activity. Rosenmai et al. (2016) also applied this technique to detect endocrine related activity of fluorinated alkyl substances and technical mixtures thereof as used in food packaging paper. Such an effect directed analysis has also been used by Veyrand et al (2017) to identify nonyl-phenol in food contact materials. As an example Bengtström completed a study on an interdisciplinary strategy for the screening and identification of compounds with potential adverse health effects in paper and board FCMs (Bengtström, 2014). A comprehensive extraction process, compatible with both chemical and toxicological analysis, was developed. The first step in this method was to test the FCM extracts for endocrine disruptive effects, genotoxicity, and metabolic effects of xenobiotics by in-vitro effect assays. The response from the AhR assay can be linked to these metabolic effects. Samples that were tested positive for these toxicity tests, were then subjected to an effect directed analysis (EDA) scheme (figure 3).

Figure 3. An effect directed analysis (EDA) scheme. Toxic fractions are isolated and analysed with LC- or GC-MS techniques. Potential toxic candidates are identified and their toxicity confirmed by bio-testing.

In this scheme a positive extract is fractionated by HPLC to reduce the number of compounds to be identified as well as the matrix effects, and subjected to a second screening of cell assays. Secondly, the positive fractions were analysed by GC-QTOF-MS and UHPLC-QTOF-MS for identification of the bioactive substances. They faced problems with the availability of libraries for the UHPLC-QTOF-MS data, thus a large part of the tentative identification had to be performed manually, whereas the identification for the GC-QTOF-MS data could by automated. Following these difficulties, Bengtström created an accurate mass database containing about 2100 compounds with reported use in paper and board, and which can be found in their report. The first step of tentative identification was a fully automated step of integration and deconvolution. Then, the quasi-molecular ions $\left([\mathrm{M}+\mathrm{H}]^{+}\right.$or $\left.[\mathrm{M}-\mathrm{H}]^{-}\right)$were located. The vendor specific software was used to find many suggestions for molecular formulas of a single $m / z$ in the spectra, after which the isotope distribution was used to select the most matching one. They concluded that both isotope distribution and hits in the accurate mass database greatly increased the possibility of a correct tentative identification. In this study, the combination of bioassays with chemical analysis resulted in the identification of compounds with endocrine disruptive effects, effects on the metabolism of xenobiotics, and mutagenic effects. Also, the concentration of the compounds found in the extracts by chemical analysis, was successfully correlated in two of the three bioassays with the originally measured toxicological effect, thus proving the value of this combination.

While several studies have demonstrated the usefulness of the application of bioassays in the safety assessment of FCMs there remain a number of future research needs. The first is the 
development, optimization and validation of methods to produce representative samples of different types of FCMs for in vitro testing. This includes the investigation of the effects of different matrices in FCM migrates. Secondly, assays for FCMs testing should be sufficiently sensitive for detecting all chemicals of concern at relevant concentration. As an example, the Ames assay in combination with a standard sample preparation method is capable of detecting only a small percentage of the genotoxic substances that may be present at levels of $0.01 \mathrm{mg} / \mathrm{kg}$ (Rainer et al., 2018; Bolognesi et al., 2017).

In an untargeted strategy a large number of compounds may be identified and it is clear that not all compounds can be tested for biologically activity. Therefore a prioritization raking for safety evaluation is urgently needed. A promising approach to detect mutagens without animal or in vitro testing lies in the application of in silico tools (Manganelli et al., 2018). In silico tools are essentially computer models, able to make predictions for a non-evaluated compound based on knowledge extracted from a collection of structurally related substances with experimental toxicity data. Quantitative structure-activity relationship (QSAR) modelling has successfully been applied to FCM by van Bossuyt et al. (2017) and Pieke et al. (2018). Van Bossuyt et al. performed a case study with printed paper and board FCM and prioritized 106 out of 1723 FCM substances by using 4 different QSAR models. This strategy can also be applied to other groups of chemicals facing the same need for priority ranking.

\subsection{Application of TTC in the assessment of unknown NIAS}

The threshold of toxicological concern (TTC) concept has been adopted within the European Union legislation as a tool to deal with unknown chemical compounds (EFSA and WHO, 2016). The TTC concept uses tentative exposure data to determine whether intake of a chemical is below an acceptable threshold of no concern, defined by assigning a Cramer class based on the chemical structure or so-called structural alerts. TTC is a preliminary assessment tool that has been applied in strategies to detect and evaluate NIAS as described by Koster et al. (2014) and Pieke et al. (2018a).

Koster et al. (2014) published an extensive report on a safety assessment strategy for detecting unknown NIAS in carton FCMs. The strategy enables one to distinguish toxicologically relevant from toxicologically less relevant substances by several toxicological assessments. The method is described as a complex mixture safety assessment strategy (CoMSAS), and uses several analytical and biological screening procedures that allow the exposure to NIAS to be estimated (Koster et al., 2015). CoMSAS is a decision tree method based on the TTC concept, and was applied by Koster et al. to 3 carton FCMs. The LOD of $10 \mu \mathrm{g} / \mathrm{kg}$ food, that is generally required and used for the detection of migrants in FCMs, has been replaced by an exposure threshold of $90 \mu \mathrm{g} /$ person/day, based on the TTC of Cramer class III substances. Since an average person consumes $1 \mathrm{~kg}$ food per day, the new threshold is increased by nine times, which substantially reduces the group of components that must be identified. The identification of unknown compounds is focussed only on those substances exceeding the threshold.

Figure 4. Complex mixtures safety assessment strategy (CoMSAS) (Koster et al., 2014)

The first step of the chemical analysis consists of a screening of compounds in the migrate extract that exceed the exposure threshold of $90 \mu \mathrm{g} /$ person/day, based on the TTC for Cramer class III substances. The analytical screening combines four different analytical techniques to ensure that as 
many NIAS as possible are detected. The present evaluation includes (1) headspace GC-MS (EI) for volatile substances, (2) GC-MS (EI) for semi-volatile substances, (3) derivatisation of non-volatiles followed by GC-MS (EI) analysis, and (4) LC coupled to an evaporative light scattering detector (UV/ELSD) for analysis of non-volatiles. Since it is almost impossible to incorporate chemical standards, detectors are used that give a uniform response so that a semi-quantitative estimate of the migration can be made. Whenever in LC-ELDS analysis a compound exceeds the threshold of $90 \mu \mathrm{g} /$ day, it will be identified by GC- and LC-MS. After the analytical screening, an exclusion of known highly toxic substances and substances that are excluded from the TTC concept was performed as the second step. The presence of the following substances was examined: aflatoxinlike substances, $\mathrm{N}$-nitroso substances, azoxy substances, polyhalogenated dibenzo- $p$-dioxins, dibenzofurans and -biphenyls, steroids, non-essential metals, high molecular weight substances, and organophosphates and carbamates. The third step includes a genotoxicity assessment of the migration extract by means of a BlueScreen $\mathrm{HC}$ bioassay. When the bioassay presents a negative response, it can be assumed that there are no genotoxic compounds present and further identification of compounds is not required. When the bioassay does give a positive response for genotoxicity, additional work must be performed to identify the substance(s). Identification is then done by fractionation of the extract by size-exclusion chromatography (SEC), which results in a limited amount of substances per fraction, after which the fractions are submitted to a second bioassay. The fraction that then gives a positive response for genotoxicity is further analysed. The introduction of an exposure threshold provides a pragmatic way for efficient screening for toxicological relevant NIAS in paper and board FCMs and reduces the effort the analytical chemist and toxicologist have to make in the whole process.

Another approach is proposed by Pieke et al. (2018a). They realized that a risk assessment of NIAS is most of the time not possible since much information is missing. This was also concluded by Muncke et al (2017). Most NIAS do not have assigned chemical structures, concentration data or characterization of hazards. In a recent series of publications Pieke et al. (2017, 2018a, 2018b) described the use of explorative methods to determine NIAS in food contact materials and concluded that untargeted analytical strategies are useful to estimate the concentration and chemical structure of NIAS. However, a comprehensive analysis of all compounds found via exploration is not realistic and therefore a risk prioritization is required to identify the compounds that most likely have adverse health effects.

Analysis of cardboard extracts was done using LC/Q-ToF-MS. Semi-quantification as described by Pieke et al. (2017) was used to determine estimated concentrations of chromatographically eluting chemical substances and was limited to the 1200 largest peaks in the chromatogram. The chemical structure of compounds in the sample extract was determined by recording fragmentation spectra and using structure correlations to propose a best matching chemical compound (Pieke et al., 2018b). The tentative identification results were later combined with the semi-quantification results by comparing exact mass and retention time. Possible adverse health effects of the tentatively identified compounds were predicted using quantitative structure-activity relationship (QSAR) models. The three endpoints that were defined were carcinogenicity, mutagenicity and reproductive toxicity, and only the likely activity of the chemical compound was predicted. A tentative exposure assessment is made by comparing the semi-quantitative concentration of the chemical compound with the exposure limit of the TTC approach for this compound structure. The result is the TTC excess factor, which is the fraction of exposure compared to the threshold, i.e. a TTC excess of $100 \%$ means the predicted intake is equal to the threshold from the TTC approach. Finally, a decision tree is used for risk prioritization and risk profile classification. The chemical compounds are subdivided into three priority classes following a so-called decision unit, which is an expertisedriven decision tool. The resulting risk profile (low, high and insufficient data/no consensus) can be used to prioritize further risk assessments. 
When compared, the CoMSAS method relies on analytical techniques that have a more or less uniform response for different compounds while the method of Pieke et al. uses a special technique of quantification markers to make the response of compounds in the LC/MS analyses more uniform. The CoMSAS method also uses more analytical techniques to detect a broader spectrum of NIAS. The main difference however is in the use of bioassays in the CoMSAS method to detect adverse health effects where the method of Pieke et al. uses QSAR techniques to predict potential adverse health effects. When the bioassay in the CoMSAS method is negative no further identifications of NIAS is needed while in the method of Pieke et al. all NIAS will have to be identified to perform the QSAR testing. Since the latter also brings a number of uncertainties the CoMSAS method may give more certainty in NIAS testing.

\section{Conclusions}

Analysis of NIAS was found to be very challenging since their presence and identity is often not known. The major sources of compounds found in paper and board are components from printing inks, adhesives, sizing agents, surface coatings, impurities in the raw materials and from the manufacturing process. Several studies have been performed to compare fresh and recycled paper fibres and the results showed that recycled fibres contain more mineral oils, impurities, and overall more NIAS.

To prepare FCMs for analysis, various protocols using different solvents and diverse time and temperature conditions have been applied. In short one can conclude that the contact conditions fall into two categories, namely "migration", when the conditions resemble the actual use, and "extraction" when the conditions promote a strong interaction with an FCM. Migration studies under worst case conditions are based on solid-liquid extraction and are generally performed with food simulants like water for wet foods, ethanol for fatty foods and Tenax as a food simulant for dry foods. Extraction studies of paper and board FCMs have been performed in similar ways, extraction of volatile compounds with HS or HS-SPME analysis, and of non-volatiles by Soxhlet or ultrasound assisted solvent extraction. Clean-up methods for NIAS extracted from paper and board are SPE or simple centrifugation followed by filtration. To reduce the complexity of sample extracts a fractionation step using HPLC, SEC, or SPE is used in some analysis.

For the analysis of NIAS two strategies are applied: targeted analytical methods for the analysis of predicted and known NIAS, and untargeted or screening methods to analyse unknown NIAS which may have a wide range of physical/chemical properties. Targeted analysis are performed using GCMS based methods for volatile NIAS and GC- and LC-MS based methods for semi- and non-volatile NIAS. Derivatization, mostly silylation, is sometimes applied to analyse non-volatiles with GC-MS. For the identification of the targeted NIAS dedicated compound libraries are used. An untargeted analysis is performed to identify as many as possible compounds in a migrate or extract of paper and board FCMs, especially NIAS that cannot be predicted beforehand, which makes it a challenging task. This type of analysis is mostly done using GC and LC techniques in combination with high resolution mass spectrometry techniques like Orbitrap or QTOF mass spectrometry. These high resolution accurate mass spectrometers are favoured because of the complexity of the sample extracts and are preferably operated in full scan for untargeted analysis. Often software is used to generate elemental formulas for the accurate masses of the detected compound peaks. The identification of analytes in a GC- or LC-MS analysis is generally done with the help of compound libraries and databases like PubChem $®$, ChemSpider $\circledast$ and SciFinder $\AA$. A number publication contain homemade databases of compounds that are typically used in printing inks, adhesives, sizing agents and surface coatings. 
In untargeted analysis in silico tools are gaining importance in the identification of NIAS. Recent publications describe the use of so-called explorative methods, an untargeted analytical strategy to estimate the concentration and chemical structure of NIAS. However, a comprehensive analysis of all compounds found via exploration is not realistic and therefore a risk prioritization is required to identify the compounds that most likely have adverse health effects. Possible adverse health effects of the tentatively identified compounds were predicted using QSAR models and a TTC approach. Finally, a tentative exposure assessment is made by comparing the semi-quantitative concentration of the chemical compound with the estimated exposure limit from the QSAR models or TTC approach. While a lot of NIAS may be (tentatively) identified using these methods, an even large number is often not identified or multiple identifications (multiple molecular structures) are found for the same compound peak. As a result, the most promising application of in silico methods is its use in priority setting upon screening of a large number of compounds.

The combination of bioassays with sensitive analytical techniques, effect directed analysis, seems to be the most promising and efficient way of identifying NIAS and their hazard to human exposure. In vitro bioassay based testing allows for a rapid evaluation of multiple toxicological endpoints. In addition it allows the determination of a combined effect of all detected compounds, including the unknowns, in a sample. Positive sample extracts or fractions thereof can be further analysed with GC- or LC-HRMS techniques to identify the toxic compounds. Future research is required into the selection of the bioassay. The selected bioassay should not only be sensitive enough for detecting all compounds of concern in the FCM extract at a relevant concentration level, it should also have relevance with human health. CoMSAS is an example of a successful approach for the detection and identification of unknown NIAS in complex samples. It combines the sensitivity of analytical techniques with the ability of testing for cytotoxicity, genotoxicity and endocrine disruptors in one method. The number of analytes that have to be identified is reduced by using a threshold based on the relevant TTC instead of using the generic migration limit or LOD of $10 \mu \mathrm{g} / \mathrm{kg}$ food. By identifying substances of highest concern, the resources available for experimental testing can be attributed in a more efficient way.

\section{Declaration of interest}

The authors declare that they have no competing interests. This research did not receive any specific grant from funding agencies in the public, commercial, or not-for-profit sectors.

\section{References}

Alin J., \& Hakkarainen M. (2011). Microwave heating causes rapid degradation of antioxidants in polypropylene packaging, leading to greatly increased specific migration to food simulants as shown by ESI-MS and GC-MS, Journal of Agricultural and Food Chemistry, 59, 5418-5427.

Aznar, M., Rodriguez-Lafuente, A., Alfaro, P., Nerin, C. (2012). UPLC-Q-TOF-MS analysis of nonvolatile migrants from new active packaging materials, Analytical and Bioanalytical Chemistry, 404, 1945-1957.

Aznar, M., Alfaro, P., Nerín, C., Jones, E., Riches, E. (2016). Progress in mass spectrometry for the analysis of set-off phenomena in plastic food packaging materials, Journal of Chromatography $A$, $1453,124-133$. 
Bengtström, L. (2014). Chemical identification of contaminants in paper and board food contact materials, Thesis Technical University of Denmark, Denmark.

Bengtström, L., Trier, X., Granby, K., Rosenmai, A. K., Petersen J. H. (2014). Fractionation of extracts from paper and board food contact materials for in vitro screening of toxicity. Food Additives \& Contaminants: Part A, 31, 1291-1300.

Bengtström, L., Rosenmai, A. K., Trier, X., Jensen, L. K., Granby, K., Vinggaard, A. M., Driffield, M., Højslev Petersen, J. (2016). Non-targeted screening for contaminants in paper and board foodcontact materials using effect-directed analysis and accurate mass spectrometry, Food Additives \& Contaminants: Part A, 33, 1080-1093.

Bentayeb, K., Batlle, R., Romero, J., Nerín, C. (2007). UPLC-MS as a powerful technique for screening the nonvolatile contaminants in recycled PET, Analytical and Bioanalytical Chemistry, 388, 10311038.

Bentayeb, K., Ackerman, L.K., Begley, T.H. (2012). Ambient ionization-accurate mass spectrometry (AMI-AMS) for the identification of non-visible set-off in food contact materials. Journal of Agricultural and Food Chemistry, 60, 1914-1920.

Bhunia, K., Sablani, S. S., Tang, J., Rasco, B. (2013). Migration of Chemical Compounds from Packaging Polymers during Microwave, Conventional Heat Treatment, and Storage, Comprehensive Reviews in Food Science and Food Safety, 12, 523-545.

Biedermann, M., \&Grob, K, (2010) Is recycled newspaper suitable for food contact materials? Technical grade mineral oils from printing inks. European Food Research and Technology, 230, 785-796.

Biedermann, M., \& Grob, K. (2013a). Is comprehensive analysis of potentially relevant migrants from recycled paperboard into foods feasible?, Journal of Chromatography A, 1272, 106-115.

Biedermann, M., \& Grob, K. (2013b). Assurance of safety of recycled paperboard for food packaging through comprehensive analysis of potential migrants is unrealistic, Journal of Chromatography $A$, 1293, 107-119.

Bignardi, C., Cavazza, A., Corradini, C., Salvadeo, P. (2014). Targeted and untargeted data-dependent experiments for characterization of polycarbonate food-contact plastics by ultra-high performance chromatography coupled to quadrupole orbitrap tandem mass spectrometry. Journal of Chromatography A, 1372, 133-134.

Bignardi, C., Cavazza, A., Laganà, C., Salvadeo, P., Corradini, C. (2017). Release of non-intentionally added substances (NIAS) from food contact polycarbonate: Effect of ageing, Food Control, 71, 329-335.

Bignardi, C., Cavazza, A., Laganá, C., Salvadeo, P., Corradini, C. (2018). Optimization of mass spectrometry acquisition parameters for determination of polycarbonate additives, degradation products, and colorants migrating from food contact materials to chocolate. Journal of Mass Spectrometry, 53, 83-90.

Bolognesi, C., Castoldi, A.F., Crebelli, R., Barthélémy, E., Maurici, D., Wölfle, D., Volk, K., Castle, L. (2017). Genotoxicity testing approaches for the safety assessment of substances used in food 
contact materials prior to their authorization in the European Union. Environmental and Molecular Mutagenesis, 58, 361-374.

Bradley, E. L., Honkalampi-Hamalainen, U., Weber, A., Andersson, M. A., Bertaud, F., Castle, L., DahIman, O., Hakulinen, P., Hoornstra, D., Lhuguenot, J. C. (2008). The BIOSAFEPAPER project for in vitro toxicity assessments: Preparation, detailed chemical characterisation and testing of extracts from paper and board samples, Food and Chemical Toxicology, 46, 2498-2509.

Bradley, E. L., Stratton, J. S., Leak, J., Lister, L., Castle, L. (2013). Printing ink compounds in foods: UK survey results, Food Additives \& Contaminants: Part B, 6, 73-83.

Brenz, F., Linke, S., Simat, T. (2016). Qualitative and quantitative analysis of monomers in polyesters for food contact materials, Food Additives \& Contaminants: Part A, 34, 307-319.

Burman, L., Albertsson, A. C., Höglund, A. (2005). Solid-phase microextraction for qualitative and quantitative determination of migrated degradation products of antioxidants in an organic aqueous solution, Journal of Chromatography A, 1080, 107-116.

Canellas, E., Aznar, M., Nerín, C., Mercea, P. (2010a). Partition and diffusion of volatile compounds from acrylic adhesives used for food packaging multilayers manufacturing, Journal of Materials Chemistry, 20, 5100-5109.

Canellas, E., Nerín, C., Moore, R., Silcock, P. (2010b) New UPLC coupled to mass spectrometry approaches for screening of non-volatile compounds as potential migrants from adhesives used in food packaging materials, Analytica Chimica Acta, 666, 62-69.

Canellas, E., Vera, P., Domeño, C., Alfaro, P., Nerín, C. (2012). Atmospheric pressure gas chromatography coupled to quadrupole-time of flight mass spectrometry as a powerful tool for identification of non intentionally added substances in acrylic adhesives used in food packaging materials, Journal of Chromatography A, 1235, 141-148.

Canellas, E., Vera, P., Nerín, C. (2015). UPLC-ESI-Q-TOF-MS(E) and GC-MS identification and quantification of non-intentionally added substances coming from biodegradable food packaging, Analytical and Bioanalytical Chemistry, 407, 6781-6790.

Castle, L., Offen, C. P., Baxter, M. J., Gilbert, J. (1997a). Migration studies from paper and board food packaging materials. Part 1. Compositional analysis," Food Additives \& Contaminants, vol. 14, no. 1, pp. 35-44, 1997.

Castle, L.,Damant, A.P., Honeybone, C.a., Johns, S.M., Jickells, S.M., Sharman, M., Gilbert, J. (1997). Migration studies from paper and board food packaging materials. Part 2. Survey for residues of dialkylamino benzophenone UV-cure ink photoinitiators. Food Additives \& Contaminants, 14, 45 52.

Chalbot, M.C., Vei, I., Lykoudis, S., Kavouras I.G. (2006). Particulate polycyclic aromatic hydrocarbons and n-alkanes in recycled paper processing operations, Journal of Hazardous Materials, 137, 742751.

Choi, J. O., Jitsunari, F., Asakawa, F., Park, H. J., Lee, D. S. (2002). Migration of surrogate contaminants in paper and paperboard into water through polyethylene coating layer, Food Additives \& Contaminants, 19, 1200-1206. 
Clemente I., Aznar, M., Nerin, C., Bosetti O. (2016). Migration from printing inks in multilayer food packaging materials by $\mathrm{GC} / \mathrm{MS}$ analysis and pattern recognition chemometrics. Food Addities \& Contaminants, 33, 703-714. DOI.org/10.1080/19440049.2016.1155757.

Coulier, L., Bradley, E. L., Bas, R., Verhoekx, K., Driffield, M., Harmer, N., Castle, L. (2010). Analysis of reaction products of food contaminants and ingredients: Bisphenol $A$ diglycidyl ether (BADGE) in canned foods, Journal of Agricultural and Food Chemistry, 58, 4873-4882.

Diehl, H., Welle, F. (2015). How to determine functional barrier performance towards mineral oil contaminants from recycled cardboard. Food Packag. Shelf Life, 5, 41-49.

EFSA (2016). Recent developments in the risk assessment of chemicals in food and their potential impact on the safet assessment of substances used in food contact materials. EFSA Journal, 14, 4357. https://doi.org/10.2903/j.efsa.2016.4357.

EFSA/WHO (2016). Review of the threshold of toxicological concern (TTC) approach and development of a new TTC decision tree. EFSA Support. Publ. 2016 EN-1006 1-50. https://doi.org/10.2903/SP.EFSA.2016.EN-1006.

Eicher, A., Biedermann, M., Zurfluh, M., Grob, K. (2015). Migration by 'direct' or 'indirect' food contact? 'Dry' and 'wetting' foods? Experimental data for 'touching' contact of dry foods with paper and board. Food Additives \& Contaminants: Part A, 32, 110-119.

European Commission. (2011). Commission regulation (EU) No 10/2011 on plastic materials and articles intended to come into contact with food. Official Journal of the European Union, 2, 1-12.

Ewender, J., Franz, R., Welle, F. (2013). Permeation of Mineral Oil Components from Cardboard Packaging Materials through Polymer Films, Packaging and Technology and Science, 26, 423-434.

Félix, J. S., Isella, F., Bosetti, O., Nerín, C. (2012). Analytical tools for identification of non-intentionally added substances (NIAS) coming from polyurethane adhesives in multilayer packaging materials and their migration into food simulants, Analytical and Bioanalytical Chemistry, 403, 2869-2882.

Fierens T., Servaes, K., Van Holderbeke, M., Geerts, L., De Henauw, S., Sioen, I., Vanermen, G. (2012). Analysis of phthalates in food products and packaging materials sold on the Belgian market, Food and Chemical Toxicology, 50, 2575-2583.

Fiselier, K., Grundbock, F., Schon, K., Kappenstein, O., Pfaff, K., Hutzler, C., Luch, A., Grob, K. (2013). Development of a manual method for the determination of mineral oil in foods and paperboard. Journal of Chromatography A, 1271, 192-200.

Geueke, B. (2013). Dossier - Non-intentionally added substances ( NIAS ), Food Packaging Forum, DOI 10.5281/zenodo.33514.

Geueke, B., Groh, K., and Muncke, J. (2018). Food packaging in the circular economy: Overview of chemical safety aspects for commonly used materials. Journal of Cleaner Product, 193, 491-505. DOI:org/10.1016/j.jclepro.2018.05.005

Groh, K.J., Muncke, J. (2017). In vitro testing of food contact materiale: State-of-the-art and future challenges. Comprehensive reviews in food science and food safety, 16, 1123-1150. 
Groh, K.J., Geueke, B., Muncke, J. (2017). Food contact materials and gut health: Implications for toxicity assessment and relevance of high moleculat weight migrants. Food and Chemical Toxicology, 109, 1-18.

Honkalampi-Hämäläinen, U., Bradley, E. L., Castle, L., Severin, I., Dahbi, L., Dahlman, O., Lhuguenot , J.C., Andersson, M.A., Hakulinen, P., Hoornstra, D., Mäki-Paakkanen, J., Salkinoja-Salonen, M., Turco, L., Stammati, A., Zucco, F., Weber, A., von Wright, A. (2010). Safety evaluation of food contact paper and board using chemical tests and in vitro bioassays: Role of known and unknown substances, Food Additives \& Contaminants: Part A, 27, 406-115.

Jurek, A., Leitner, E. (2017). Analytical determination of bisphenol A (BPA) and bisphenol analogues in paper products by GC-MS/MS. Food Additives \& Contaminants: Part A, 34, 1225-1238.Kassouf, A., Maalouly, J., Chebib, H., Rutledge, D. N., Ducruet, V. (2013). Chemometric tools to highlight nonintentionally added substances (NIAS) in polyethylene terephthalate (PET), Talanta, 115, 928-937.

Koivikko, R., Pastorelli, S., Rodriquez-Bernaldo de Quirós, A., Paseiro-Cerrato, R., Paseiro-Losada, P., Simoneau, C. (2010). Rapid multi-analyte quantification of benzophenone, 4methylbenzophenone and related derivatives from paperboard and food packaging, Food Additives \& Contaminants, 10, 1478-1486.

Koster, S., Rennen, M., Leeman, W., Houben, G., Muilwijk, B., van Acker, F., Krul, L. (2014). A novel safety assessment strategy for non-intentionally added substances (NIAS) in carton food contact materials, Food Additives \& Contaminants: Part A, 31, 422-443.

Koster, S., Bani-Estivals, M. H., Bonuomo, M., Bradley, E., Chagnon, M. C., Garcia, M. L., Godts, F., Gude, T., Helling, R., Paseiro-Losada, P., Pieper, G., Rennen, M., Simat, T., Spack, L. (2015). Guidance of Best Practices on the Risk Assessment of NIAS in Food Contact Materials and Articles, ILSI Europe Report Series. 2015, 1-70.

Leeman, W., Krul L. (2015). Non-intentionally added substances in food contact materials: How to ensure consumer safety, Current Opinion in Food Science, 6, 33-37.

Lopez-Espinosa, M. J., Granada, A., Araque, P., Molina-Molina, J. M., Puertollano, M. C., Rivas, A., Fernández, M., Cerrillo, I., Olea-Serrano, M. F., López, C., Olea, N. (2007). Oestrogenicity of paper and cardboard extracts used as food containers, Food Additives \& Contaminants, 24, 95-102.

Manganelli, S., Schilter, B., Benfenati, E., Manganaro, A., Lo Piparo, E. (2018). Integrated strategy for mutagenicity prediction applied to food contact chemicals. ALTEX, 35, 169-178.

Martínez-Bueno, M.J., Hernando, M. D., Uclés, S., Rajski, L., Cimmino, S., Fernández-Alba, A. R. (2017). Identification of non-intentionally added substances in food packaging nano films by gas and liquid chromatography coupled to orbitrap mass spectrometry, Talanta, 172, 68-77.

Mattarozzi, M., Lambertini, F., Suman, M., Careri, M. (2013). Liquid chromatography-full scan-high resolution mass spectrometry-based method towards the comprehensive analysis of migration of primary aromatic amines from food packaging, J. Chromatogr. A. 1320, 96-102.

Moret, S., \& Conchione, C. (2018). Mineral Oils in Food: Major Sources and Analytical Determination. Food Nutr J: FDNJ-165. DOI: 10.29011/2575-7091.

Moreta, C., Tena, M.T. (2014). Determination of perfluorinated alkyl acids in corn, popcorn and popcorn paper bags before and after cooking by ultrasound solid-liquid extraction, liquid chromatography and quadrupole-time of flight mass spectrometry. J. Chromatogr. A. 1355, 211218. 
Mottier, P., Frank, N., Dubois, M., Tarres, A., Bessaire, T., Romero, R., Delatour, T. (2014). LC-MS/MS analytical procedure to quantify tris(nonylphenyl)phosphite, as a source of the endocrine disruptors 4-nonylphenols, in food packaging materials, Food Additives \& Contaminants: Part A, 31, 962-972.

Muncke, J. (2011). Endocrine disrupting chemicals and other substances of concern in food contact materials: An updated review of exposure, effect and risk assessment, Journal of Steroid Biochemistry \& Molecular Biology, 127, 118-127.

Muncke, J. (2012). Food Packaging Materials, Food Packaging Forum. Available at: http://www.foodpackagingforum.org/food-packaging-health/food-packaging-materials. (Accessed: 08-Sep-2017).

Muncke, J., Backhaus, T., Geueke, B., Maffini, M.V., Martin, O.V., Peterson Myers, J., Soto, A.M., Trasande, L., Trier, X., Scheringer, M. (2017). Scientific Challenges in the Risk Assessment of Food Contact Materials. Environmental Health Perspectives. https://doi.org/10.1289/EHP644.

Nerin, C., Asensio, E. (2004). Behaviour of organic pollutants in paper and board samples intended to be in contact with food. Analytica Chimica Acta, 508, 185-191.

Nerin, C., Alfaro, P., Aznar, M., Domeño C. (2013). The challenge of identifying non-intentionally added substances from food packaging materials: A review, Analytica Chimica Acta, 775, 14-24.

Nguyen, P.M., Julien, J.M., Breysse, C., Lyathaud, C., Thébault, J., Vitrac, O. (2017). Project SafeFoodPack Design: Case study on indirect migration from paper and boards. Food Additives \& Contaminants, 34, 1703-1720. DOI: org/10.1080/19440049.2017.1315777.

Omer, E., Cariou, R., Remaud, G., Guitton, Y., Germon, H., Hill, P., Dervilly-Pinel, G., Le Bizec, B. (2018). Elucidation of non-intentionally added substances migrating from polyester-polyurethane lacquers using automated LC-HRMS data processing. Anal. Bioanal. Chem. DOI: 10.1007/s00216018-0968-z.

Ozaki, A., Yamaguchi, Y., Fujita, T., Kuroda, K., Endo, G. (2005). Safety assessment of paper and board food packaging: Chemical analysis and genotoxicity of possible contaminants in packaging, Food Additives \& Contaminants, 22, 1053-1060.

Parigoridi, I. E., Akrida-Demertzi, K., Demertzis, P. G. (2014). Determination of Five (5) Possible Contaminants in Recycled Cardboard Packages and Food Simulants Using Ultrasound Assisted Extraction Coupled to GC-MS, Materials Sciences and Applications, 5, 745-751.

Pérez-Palacios, D., Fernández-Recio, M. A., Moreta, C., Tena, M. T. (2012). Determination of bisphenol-type endocrine disrupting compounds in food-contact recycled-paper materials by focused ultrasonic solid-liquid extraction and ultra performance liquid chromatography-high resolution mass spectrometry, Talanta, 99, 167-174.

Pezo, D., Fedeli, M., Bosetti, O., Nerín, C. (2012). Aromatic amines from polyurethane adhesives in food packaging: The challenge of identification and pattern recognition using Quadrupole-Time of Flight-Mass Spectrometry, Analytica Chimica Acta, 756, 49-59.

Pieke, E.N., Granby, K., Trier, X., Smedsgaard, J. (2017). A framework to estimate concentration of potentially unknown substances by semi-quantification in liquid chromatography electrospray ionization mass spectrometry. Analytica Chimica Acta, 975, 30-41. 
DOI.org/10.1016/j.aca.2017.03.054.

Pieke, E.N., Granby, K., Teste, B., Smedsgaard, J., Riviére G. (2018a). Prioritization before risk assessment: The viability of uncertain data on food contact materials. Regulatory Toxicology and Pharmacology, doi: 10.1016/j.yrtph.2018.06.012.

Pieke, E.N., Smedsgaard, J., Granby, K. (2018b). Exploring the chemistry of complex samples by tentative identification and semi-quantification: a food contact material case. J. Mass Spectrom., 53, 323-335. DOI.org/10.1002/jms.4052.

Pivnenko, K., Eriksson, E., Astrup T.F. (2015). Waste paper for recycling: Overview and identification of potentially critical substances. Waste Management, 45, 134-142.

Rainer, B., Pinter, E., Czerny, T., Riegel, E., Kirchnawy, C., Marin-Kuan, M., Schilter, B., Tacker M. (2018). Suitability of the Ames test to characterise genotoxicity of food contact material migrates. Food Additives \& Contaminants: Part A, DOI, org/10.1080/19440049.2018.1519259.

Rosenmai, A.K., Bengtsröm, L., Taxvig, C., Trier, X., Petersen, J.H., Svingen, T., Binderup, M.L., van Vugt-Lussenburg, B.M.A., Dybdahl, M., Granby, K., Vinggaard, A.M. (2017). An effect-directed strategy for characterizing emerging chemicals is food contact materials made from paper and board. Food and Chemical Toxicology. 106, 250-259.

Rosenmai, A.K., Taxvig, C., Svingen, T., Trier, X., van Vugt-Lussenburg B.M.A., Pedersen, M., Lesné, L., Jégou, B., Vinggaard, A.M. (2016). Fluorinated alkyl substances and technical mixtures used in food paper-packaging exhibit endocrine-related activity in vitro. Andrology, 4, 662-672.

Rubio, L., Sarabia, L. A., Herrero, A., Ortiz, M. C. (2012). Advantages of a programmed temperature vaporizer inlet and parallel factor analysis in the determination of triazines in the presence of nonintentionally added substances by gas chromatography, Analytical and Bioanalytical Chemistry, 403, 1131-1143.

Sanchis, Y., Yusà, V., Coscollà C. (2017). Analytical strategies for organic food packaging contaminants, Journal of Chromatography A, 1490, 22-46.

Schaider, L.A., Balan, S.A., Blum, A., Andrews, D.Q., Strynar, M.J., Dickinson, M.E., Lunderberg, D.M., Lang, J.R., Peaslee, G.F. (2017). Fluorinated compounds in U.S. fast food packaging. Environmental Science and Technology Letters. 4, 105-111.

Severin, I., Souton, E., Dahbi, L., Chagnon M. C. (2017). Use of bioassays to assess hazard of food contact material extracts: State of the art, Food and Chemical Toxicology, 105, 429-447.

Suciu, N. A., Tiberto, F., Vasileiadis, S., Lamastra, L., Trevisan, M. (2013). Recycled paper-paperboard for food contact materials: Contaminants suspected and migration into foods and food simulant, Food Chemistry, 141, 4146-4151.

Trier, X., Granby, K., Christensen, J. H. (2011a). Polyfluorinated surfactants (PFS) in paper and board coatings for food packaging, Environmental Science and Pollution Research, 18, 1108-1120.

Trier, X., Nielsen, N. J., Christensen, J. H. (2011b). Structural isomers of polyfluorinated di- and trialkylated phosphate ester surfactants present in industrial blends and in microwave popcorn bags, Environmental Science and Pollution Research, 18, 1422-1432.

Van Bossuyt, M., Van Hoeck, E., Vanhaecke, T., Rogiers, V., Mertens B. (2016). Printed paper and board food contact materials as a potential source of food contamination, Regulatory Toxicology and Pharmacology, 81, 10-19. 
Van Bossuyt, M., Van Hoeck, E., Raitano, G., Manganelli, S., Braeken, E., Ates, G., Vanhaecke, T., Van Miert, S., Benfenati, E., Mertens, B., Rogiers, V. (2017). (Q)SAR tools for priority setting: a case study with printed paper and board food contact material substances. Food Chem. Toxicol., 102, 109-119.

Van den Houwe, K., Van Heyst, A., Evrard, C., Van Loco, J., Bolle, F., Lynen F., Van Hoeck E. (2016). Migration of 17 Photoinitiators from Printing Inks and Cardboardinto Packaged Food - Results of a Belgian Market Survey. Packag. Technol. Sci., 29, 121-131.

Van den Houwe, K., Evrard, C., Van Loco, J., Lynen, F., Van Hoeck, E. (2017). Use of Tenax ${ }^{\circledR}$ films to demonstrate the migration of chemical contaminants from cardboard into dry food. Food Add. Contam. 34, 1261-1269.

Vavrous, L.,Vapenka, A., Sosnovcov, J., Kejlov, K., Vrbik, K., Jirov, D. (2016). Method for analysis of 68 organic contaminants in food contact paper using gas and liquid chromatography coupled with tandem mass soectrometry. Food Control, 60, 221-229.

Veyrand, J., Marin-Kuan, M., Bezencon, C., Frank, N., Guérin, V., Koster, S., Latado, H., Mollergues, J., Patin, A., Piquet, D., Serrant, P., Varela, J., Schilter, B. (2017). Integrating bioassays and analytical chemistry as an improved approach to support safety assessment of food contact materials. Food Additives \& Contaminants: Part A, 34, 1807-1816, DOI: 10.1080/19440049.2017.1358466.

Weber, A., Bradley, E., Renn, O., Schweizer, P. J. (2006). Biosafepaper - Application of Bioassays for Safety Assessment of Paper and Board for Food Contact, 2006.

Yang, Y., Hu C., Zhong, H., Chen, X., Chen, R., Yam K. L. (2016). Effects of Ultraviolet (UV) on Degradation of Irgafos 168 and Migration of Its Degradation Products from Polypropylene Films, Journal of Agricultural and Food Chemistry, 64, 7866-7873.

Yuan, G., Peng, H., Huang, C., Hu, J. (2016). Ubiquitous occurence of fluorotelomer alcohols in ecofriendly paper-made food contact materials anf their implication for human exposure. Environmental Science and Technology, 50, 942-950. 
Table 1: An overview of publications that describe targeted analytical methods for certain compounds or classes of compounds in paper and/or board FCMs.

\begin{tabular}{|c|c|c|c|}
\hline Compound(s) & Sample & Analytical technique & Reference \\
\hline Adhesives & $\begin{array}{l}\text { Laminated made of paper-adhesive- } \\
\text { substrate }\end{array}$ & APGC-QTOF-MS & Canellas et al., 2012 \\
\hline $\begin{array}{l}\text { Anthracene, benzophenone, dimethyl phthalate, methyl } \\
\text { stearate and pentachlorophenol }\end{array}$ & Paper and paperboard & GC-FID & Choi et al., 2002 \\
\hline $\begin{array}{l}\text { Benzophenone, } 2 \text { DIPNs }\{2,6 \text { - and 2,7-diisopropylnapthalene }\} \\
\text { and } 2 \text { hydrogenated terphenyls }\{\text { m-terphenyl and o-terphenyl }\}\end{array}$ & Recycled cardboard & GC-MS & Parigoridi et al., 2014 \\
\hline BPA & Paper and cardboard & HPLC-MS & Lopez-Espinosa et al., 2007 \\
\hline BPA, BADGEs, BPF, BFDGE & Recycled paper & UPLC-QTOF-MS & Pérez-Palacios et al., 2012 \\
\hline BPA, DEHP & Recycled paper and paperboard & GC-MS & Suciu et al., 2013 \\
\hline BPA and BPA analogues & Paper & GC-MS-MS & Jurek \&Leitner, 2017 \\
\hline Chemical contaminants & Cardboard & GC-MS & Van den Houwe et al., 2017 \\
\hline Mineral oils & Paper and paperboard & HPLC-GC-FID & Biedermann \& Grob, 2010 \\
\hline Mineral oils & Cardboard & GC-FID & Ewender et al., 2013 \\
\hline Mineral oils & Recycled paper & GC-FID & Diehl et al., 2015 \\
\hline Mineral oils & Paper and paperboard & HPLC-GC-FID & Moret \& Conchione, 2018 \\
\hline NIAS & Active paper/polymer films & UPLC-QTOF-MS & Aznar et al., 2012 \\
\hline NIAS in adhesives & PU paper adhesives & HS-SPME-GC-MS & Félix et al., 2012 \\
\hline PAH and n-alkanes & Dust from paper recycling processes & GC-MS & Chalbot et al., 2006 \\
\hline PFAS & Microwave popcorn bag & UPLC-QTOF-MS (neg mode) & Trier et al., $2011 b$ \\
\hline PFAS & Popcorn bag & UPLC-QTOF-MS & Moreta \& Tena, 2014 \\
\hline PFAS & Paper & LC-MS-MS & Vavrous et al., 2016 \\
\hline PFAS & Paperboard & PIGE spectroscopy & Schaider et al., 2017 \\
\hline PFAS & Paper & UPLC-MS-MS & Yuan et al. 2016 \\
\hline Photo initiators & Cardboard & UPLC-MS-MS & Van den Houwe et al., 2016 \\
\hline Photo initiators & Paper & LC-MS-MS & Cai et al., 2017 \\
\hline Phthalates & Paper and cardboard & GC-MS & Lopez-Espinosa et al., 2007 \\
\hline Phthalates & Paper and board & Bio-assays & $\begin{array}{l}\text { Honkalampi-Hämäläinen et } \\
\text { al., } 2010\end{array}$ \\
\hline \multirow[t]{2}{*}{ Phthalates } & Foodstuffs and cardboard FCMs & GC-MS & Fierens et al., 2012 \\
\hline & Paperboard & GC-MS & Cacho et al., 2012 \\
\hline Phthalates & Paper & GC-MS-MS & Vavrous et al., 2016 \\
\hline Primary aromatic amines & PU paper adhesives & & Pezo et al., 2012 \\
\hline Primary aromatic amines & Paper/plastic laminate & UPLC-HRMS & Mattarozzi et al., 2013 \\
\hline
\end{tabular}


Printing ink compounds: benzophenone, 4-

Printed paper/board food packages

methylbenzophenone, 2-methylbenzophenone, 3-

and the foodstuffs it held

methylbenzophenone, 4-hydroxybenzophenone, 2-

hydroxybenzophenone, 4-phenylbenzophenone, methyl-2

benzoylbenzoate, 1-hydroxycyclohexyl phenyl ketone, 2-

isopropylthioxanthone, 4-isopropylthioxanthone, 2,4-diethyl-

9H-thioxanthen-9-one, 2,2-dimethoxy-2-phenylacetophenone,

2-methyl-40-(methylthio)-2-morpholinopropiophenone, 4-(4-

methylphenylthio)benzophenone, ethyl-4-

dimethylaminobenzoate, 2-ethylhexyl-4-

(dimethylamino)benzoate, N-ethyl-p-toluene-sulphonamide,

triphenyl phosphate, and di-(2-ethylhexyl)fumarate

Triazines and NIAS 
Table 2: An overview of comprehensive untargeted analytical methods used for the detection of migrants and NIAS in paper and board FCMs or food packaging materials.

\begin{tabular}{|c|c|c|c|}
\hline Compound(s) & Sample & Analytical techniques & Reference \\
\hline $\begin{array}{l}\text { 2,6-di-tert-butyl-4-hydroxyto-luene, di-tert- } \\
\text { butylphenol, benzophenone,4,4'- } \\
\text { bis(dimethyl amino)benzophenone } \\
\text { (Michler's ketone), triphenyl methane, } \\
\text { bicyclohexylphenylphenanthrene carboxylic } \\
\text { acid (and its methyl ester) and abietic acid }\end{array}$ & Recycled paper and board & $\begin{array}{l}\text { Headspace GC-MS } \\
\text { GC-MS } \\
\text { HPLC-DAD } \\
\text { ICP-MS }\end{array}$ & Castle et al., 1997 \\
\hline $\begin{array}{l}\text { BPA, methylparaben, abietic acid, BADGE, } \\
\text { PFOA }\end{array}$ & Non-recycled paper and recycled fibres & $\begin{array}{l}\text { HPLC (for fractionation) } \\
\text { UPLC-MS/MS (identification) }\end{array}$ & Bengtström et al., 2014b \\
\hline Dehydroabietic acid and abietic acid & Recycled paper board & $\begin{array}{l}\text { GC-MS } \\
\text { LC-MS }\end{array}$ & Ozaki et al., 2005 \\
\hline $\begin{array}{l}\text { Mercaptobenzothiazole, 1-isopropyl- } \\
\text { 2,3,4,9-tetrahydro-1H- } \beta \text {-carboline-3- } \\
\text { carboxylic acid, Rhodamine 101, } \\
\text { 2'-(Dibenzylamino)-6'-(diethylamino)-3H- } \\
\text { spiro[2-benzofuran-1,9'-xanthen]-3-one }\end{array}$ & Recycled pizza box & $\begin{array}{l}\text { UPLC-QTOF-MS } \\
\text { GC-QTOF-MS }\end{array}$ & Bengtström et al., 2016 \\
\hline Migrants from adhesives & Acrylic water-based adhesives & $\begin{array}{l}\text { UPLC-TOF-MS } \\
\text { UPLC-HDMS }\end{array}$ & Canellas et al., 2010b \\
\hline Mineral oil: MOAH, MOSH & Recycled paperboard & Online HPLC-GC-FID & Biedermann \& Grob, 2013a \\
\hline Mineral oil: MOAH, MOSH & Paperboard & Online HPLC-GC-FID & Fiselier et al., 2013 \\
\hline Mineral oils & Paper and board & $\begin{array}{l}\text { Online HPLC-GC-FID } \\
\text { GC } \times \text { GC-MS }\end{array}$ & Biedermann \& Grob, 2010 \\
\hline NIAS & Water-based biodegradable adhesives & $\begin{array}{l}\text { UPLC-QTOF-MS } \\
\text { GC-MS }\end{array}$ & Canellas et al., 2015 \\
\hline NIAS & Food packaging films & $\begin{array}{l}\text { GC-Orbitrap-MS } \\
\text { LC-Orbitrap-MS }\end{array}$ & Martinèz-Bueno et al., 2017 \\
\hline NIAS & Polyester-polyurethane lacquers & LC-HRMS & Omer et al., 2018 \\
\hline
\end{tabular}




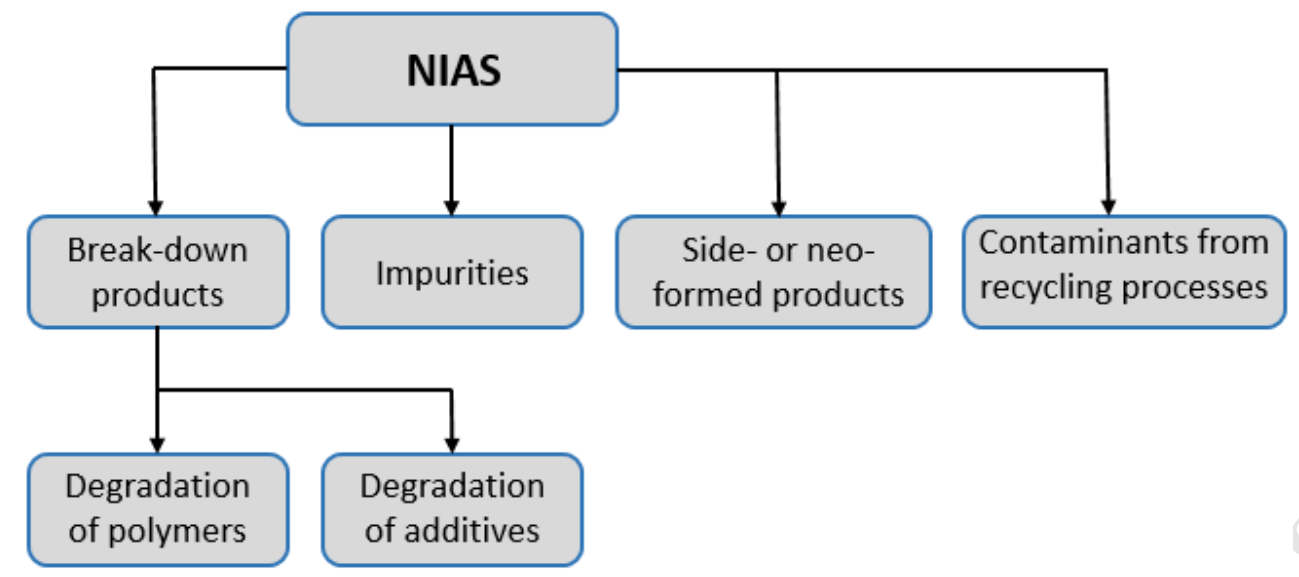

Figure 1. Classification of NIAS according to Geueke (2013). 


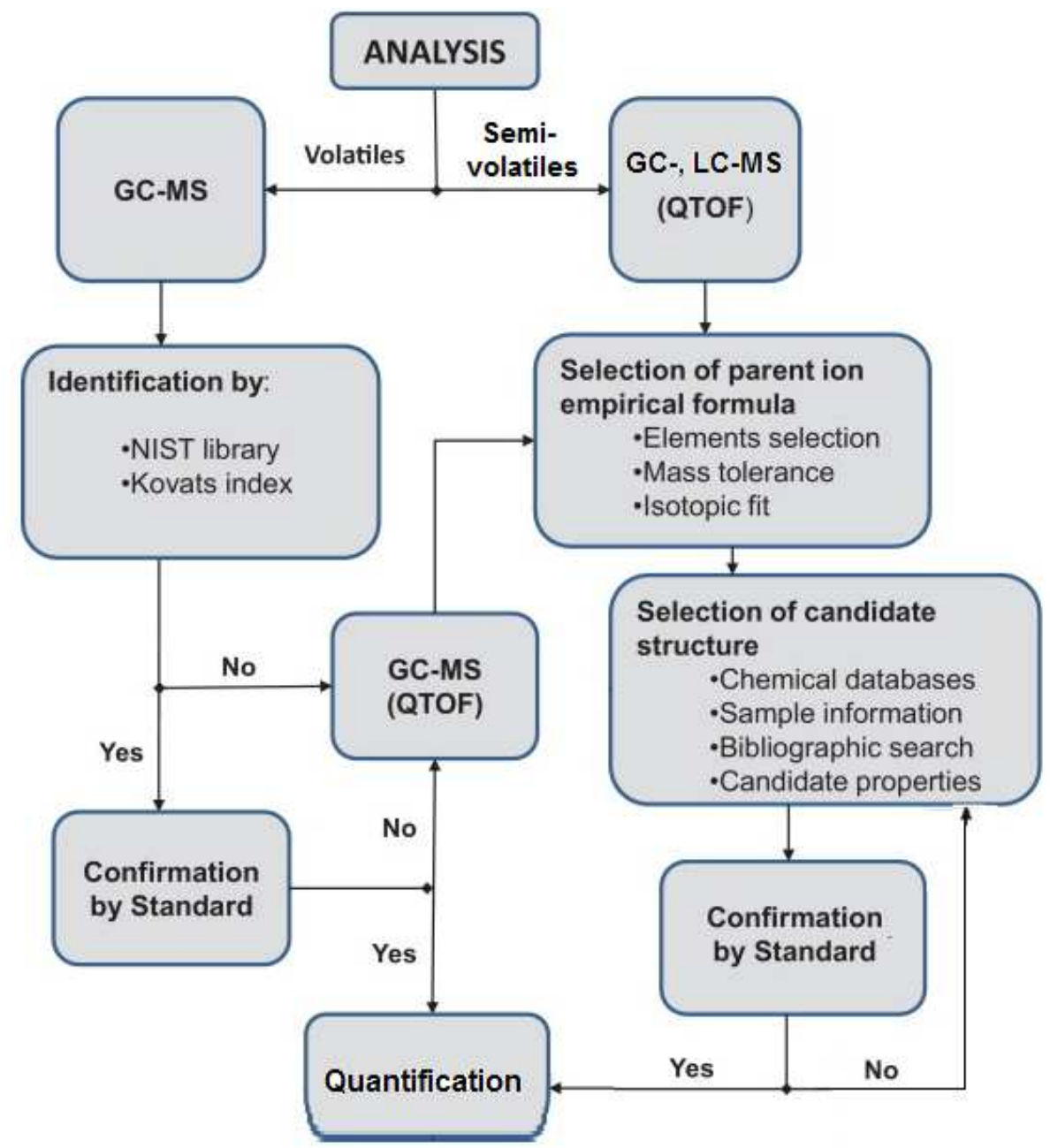

Figure 2. A decision-tree diagram for the chemical identification of NIAS. 


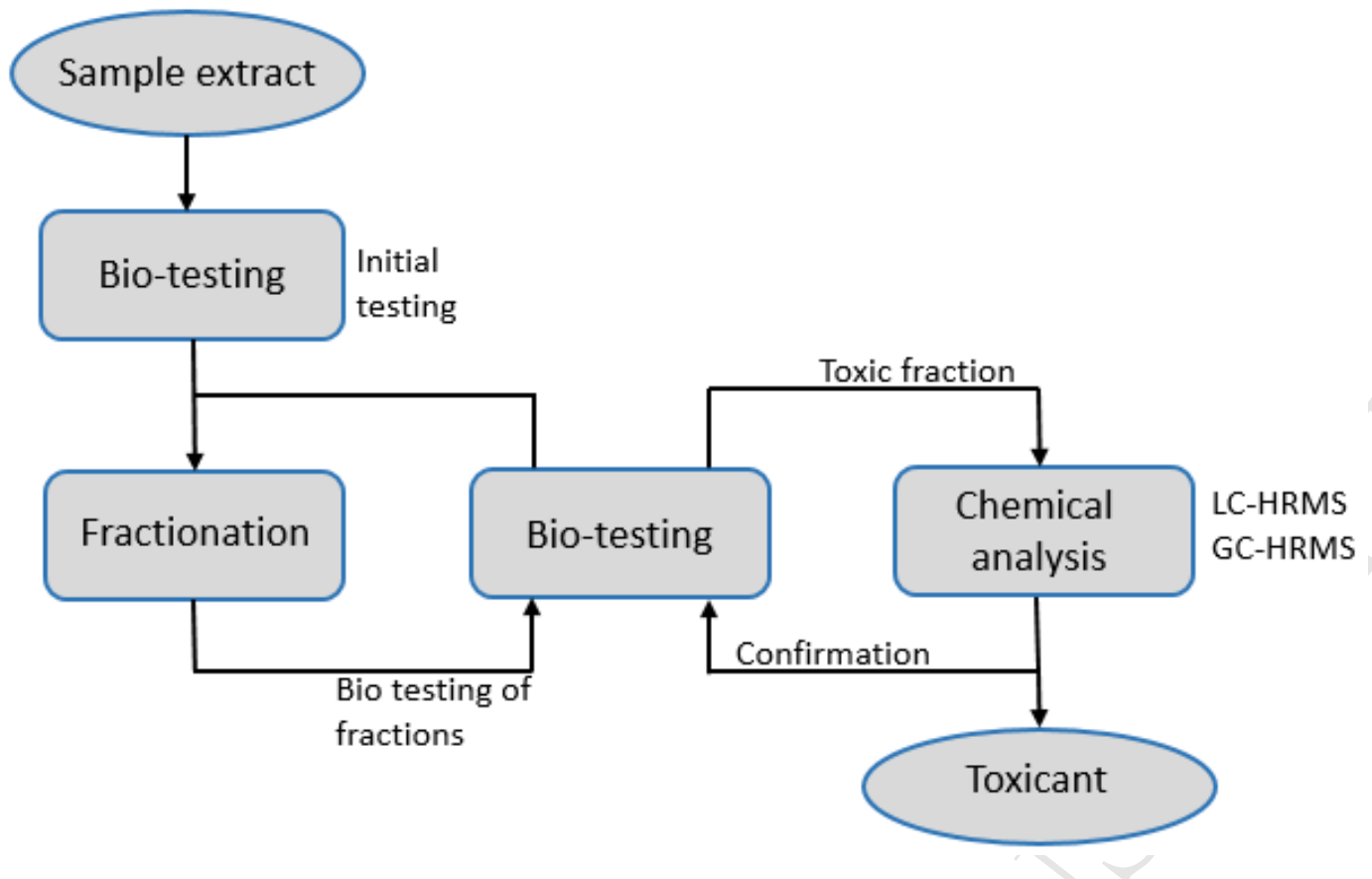

Figure 3. An effect directed analysis (EDA) scheme. Toxic fractions are isolated and analysed with LC- or GC-MS techniques. Potential toxic candidates are identified and their toxicity confirmed by bio-testing. 
Step 1 . Screening substances that exceed the exposure threshold of $90 \mu \mathrm{g}$ daily

Step 2. Exclude presence of dioxins, heavy metals and other highly toxic or TTC excluded classes of substances

Step 3. Exclude presence of structural alerts for genotoxicity or a genotoxic effect of a migration extract

Step 4. Substance specific risk assessment of substances exceeding the exposure threshold of $90 \mu \mathrm{g} /$ day and of substances detected in step $1 / 2 / 3$

Step 5. Exclude allergenic effects based on literature data and/or targeted methods for known allergens

Figure 4. Complex mixtures safety assessment strategy (CoMSAS) (Koster et al., 2014) 


\section{Review of analytical approaches for the identification of non-intentionally added substances in paper and board food contact materials}

Ruud J.B. Peters*, Iris Groeneveld, Patricia Lopez Sanchez, Wouter Gebbink, Arjen Gersen, Monique de Nijs and Stefan P. J. van Leeuwen

RIKILT - Wageningen University \& Research, 6700 AE Wageningen, The Netherlands (e-mail: ruudj.peters@wur.nl)

* Corresponding author

Highlights

The analysis of NIAS is challenging and is performed using targeted and untargeted analytical methods.

To prepare FCMs for analysis "migration" and "extraction" protocols are used.

In silico tools can provide help in assigning priority to those substances for which a comprehensive safety evaluation is most urgently needed.

A combination of bioassays and chemical analysis is used to direct the identification of unknown bioactive NIAS in complex mixtures. 